\title{
Safety of early pain relief for acute abdominal pain
}

\author{
Alex R Attard, Michael J Corlett, Nigel J Kidner, Apsara P Leslie, Ian A Fraser
}

\section{Abstract}

Objectives - (a) to determine the efficacy of papaveretum in treating pain when administered early to patients presenting with acute abdominal pain and (b) to assess its effect on subsequent diagnosis and management.

Design-Prospective, randomised, placebo controlled study.

Setting-Walsgrave Hospital, Coventry.

Subjects -100 consecutive patients with clinically significant abdominal pain who were admitted as emergencies to a surgical firm.

Interventions - Intramuscular injection of up to $20 \mathrm{mg}$ papaveretum or an equivalent volume of saline.

Outcome measures-Pain and tenderness scores, assessment of patient comfort, accuracy of diagnosis, and management decisions.

Results-Median pain and tenderness scores were lower after papaveretum (pain score 8.3 in control group and 3.1 in treatment group, $p<0.0001$; tenderness score 8.1 in control group and 5.1 in treatment group, $p<0.0001)$. Forty eight patients were deemed to be comfortable after papaveretum compared with nine after saline. Incorrect diagnoses and management decisions applied to two patients after papaveretum compared with nine patients after saline.

Conclusion-Early administration of opiate analgesia to patients with acute abdominal pain can greatly reduce their pain. This does not interfere with diagnosis, which may even be facilitated despite a reduction in the severity of physical signs. These patients should not be denied effective treatment.

\section{Introduction}

The administration of opiate analgesia by general practitioners and junior doctors to patients with acute abdominal pain seems humane but has not been conventional teaching for fear that it might mask physical signs and delay diagnosis and treatment. 'An editorial in the $B M F$ in 1979 concluded that "urgent relief of severe pain is good treatment, humane, and unlikely, to say the least, to do harm nowadays by delaying diagnosis."' Opinions were equally divided in the considerable correspondence that followed. ${ }^{3-9}$ Since then, changing attitudes have resulted in a more liberal approach to the use of analgesia in such patients, and more recent surgical textbooks claim that early pain relief might even facilitate diagnosis. ${ }^{10} 11$

Individual views on this topic are based mainly on experience and anecdotal evidence because, to date, there has been no controlled study to settle the issue. Zoltie and Cust conducted a prospective, randomised, double blind, placebo controlled trial comparing the effect of sublingual buprenorphine with placebo. ${ }^{12}$ They reported no differences in the diagnosis and management of either group of patients and concluded that early pain relief was safe. A fundamental concern with this study is that only $42 \%$ of patients were given adequate analgesia in the treatment group compared with $52 \%$ in the placebo group. Furthermore, sublingual buprenorphine is not a standard treatment for patients with acute abdominal pain. No clear conclusions can be drawn from this study.

The purpose of our study was both to assess the efficacy of papaveretum given early to patients with acute abdominal pain and to look at its effect on subsequent diagnosis and management decisions.

\section{Patients and methods}

Patients admitted as emergency cases with acute ( $<48$ hours' duration) abdominal pain sufficiently severe to warrant opiate analgesia were approached for entry into the study. Those under 16 years old and those with a suspected leaking abdominal aortic aneurysm were excluded from the study. Ethical approval was obtained from the Coventry research and ethical committee. All who participated in the study gave valid consent.

Patients were first seen by the admitting house officer, who assessed their abdominal pain and tenderness by asking them to complete a linear analogue scale (score 1). The scale ranged from 0 for no pain to $10 \mathrm{~cm}$ for the worst pain imaginable. The house officer also recorded the areas of tenderness and his or her diagnosis. If analgesia was deemed appropriate patients were asked to participate in the study. The nature and objectives of the study were explained by the house officer and were backed up by a study information sheet, which was retained by each patient. If consent was refused the reasons for refusal were noted. By opening a sealed envelope, the house officer randomly allocated consenting patients to receive a blinded intramuscular injection of up to $1 \mathrm{ml}$ of fluid containing either papaveretum $20 \mathrm{mg}$ or saline. The study was set up to have 50 patients in each treatment group. The volume of liquid injected was based on the house officer's assessment of what dose of papaveretum was appropriate for each individual patient. Patients were reviewed about one hour later by a surgical registrar, who repeated the linear analogue assessments of pain and tenderness (score 2). In addition, he assessed the patient's comfort and his confidence (as a percentage) in his diagnosis and management decision (to operate or to observe). The registrar also recorded whether he thought the patient was in the treatment or control group and whether the diagnosis or management decision was in any way compromised by including the patient in the study.

One hundred and ten patients were invited to take part in the study. Ten declined: six were worried that if their pain was relieved their symptoms would be dismissed and four had been informed by their general practitioners that their pain should not be treated before transfer to hospital because it could hamper diagnosis and upset the admitting surgeons.

Statistical analysis was performed by using the Mann-Whitney U test or two tailed Fisher's exact test, as indicated.

\section{Results}

One hundred patients were studied: 50 received papaveretum and 50 saline. Both groups were similarly 
TABLE I-Diagnosis on discharge in patients given papaveretum or saline for pain relief

\begin{tabular}{lcc}
\hline Diagnosis & $\begin{array}{c}\text { Papaveretum } \\
(\mathbf{n}=50)\end{array}$ & $\begin{array}{c}\text { Saline } \\
(\mathbf{n}=50)\end{array}$ \\
\hline Appendicitis & 11 & 9 \\
Biliary colic or acute & & \\
$\quad$ cholecystitis & 6 & 8 \\
Perforated peptic ulcer & 7 & 8 \\
Bowel obstruction & 4 & 2 \\
Diverticulitis & 5 & 4 \\
Acute pancreatitis & 2 & 5 \\
Other & 5 & 12 \\
Non-specific abdominal pain & 10 & \\
\hline
\end{tabular}

TABLE II-Median pain and tenderness scores before (score 1) and one hour after (score 2) papaveretum or saline. Interquartile ranges are given in parentheses (Mann-Whitney U test)

$\left.\begin{array}{lcc}\hline & \text { Papaveretum } & \text { Saline } \\ \hline & \text { Pain } & \\ \text { Score 1 } & 8 \cdot 8(8 \cdot 2-9 \cdot 4) & 8 \cdot 6(7 \cdot 8-9 \cdot 2) \\ \text { Score 2 } & 3 \cdot 1(1 \cdot 7-4 \cdot 6) & 8 \cdot 3(6 \cdot 7-9 \cdot 0) \\ & \text { Tendermess } & \\ \text { Score 1 } & 8 \cdot 2(7 \cdot 2-8 \cdot 9) & 8 \cdot 2(7 \cdot 4-9 \cdot 2) \\ \text { Score 2 } & 5 \cdot 1(4 \cdot 1-6 \cdot 9) & 8 \cdot 1(6 \cdot 5-9 \cdot 1)\end{array}\right\} \mathrm{p}<0 \cdot 0001$

matched for age (median age 45 in the group given papaveretum and 48 in the group given saline), sex ( 25 women in the papaveretum group and 27 in the saline group), and diagnosis on discharge (table I).

Table II shows the median pain and tenderness scores before and one hour after injection. The median pain and tenderness scores on admission (score 1) in the study group were similar to those in the control group. Median pain and tenderness scores fell significantly after papaveretum, although the fall in tenderness score was smaller. There was no placebo effect in the control group. Pain and tenderness were classified as better when the relevant score after treatment was at least $20 \%$ lower, as worse when it was $20 \%$ or more higher, and as unchanged when the difference in score before and after treatment was less than $20 \%$. With these criteria pain and tenderness were better in 47 and 35 patients after papaveretum, respectively, compared with seven and eight after saline (table III). When reviewed by the registrar after treatment 48 patients were considered to be comfortable after papaveretum compared with nine after saline $(\mathrm{p}<0.0001$, Fisher's exact test). There was no difference in the registrar's diagnostic confidence or his management decision (to operate or to observe) between the two groups (table IV).

The registrar's decision to operate or to observe was incorrect in two patients in the papaveretum group and in nine patients in the saline group ( $p=0.051$, Fisher's exact test). The registrar's initial diagnosis one hour after the injection was incorrect in all of these patients;

TABLE III-Assessment of pain and tenderness one hour after injection of papaveretum or saline (Fisher's exact test)

\begin{tabular}{|c|c|c|}
\hline & Papaveretum & Saline \\
\hline & Pain & \\
\hline $\begin{array}{l}\text { Better } \\
\text { No change/worse }\end{array}$ & $\begin{array}{l}47 \\
3 / 0\end{array}$ & $\left.\begin{array}{c}7 \\
42 / 1\end{array}\right\} p<0.0001$ \\
\hline & Tenderness & \\
\hline $\begin{array}{l}\text { Better } \\
\text { No change/worse }\end{array}$ & $\begin{array}{l}35 \\
15 / 0\end{array}$ & $\mathrm{p}<0.0001$ \\
\hline
\end{tabular}

TABLE IV-Confidence of surgical registrar in his ability to reach a diagnosis and decide management one hour after injection of papaveretum or saline. Values are median percentages (ranges)

\begin{tabular}{lrr}
\hline & Papaveretum & \multicolumn{1}{c}{ Saline } \\
\hline $\begin{array}{l}\text { Diagnosis } \\
\text { Management }\end{array}$ & $90(48-100)$ & $90(50-100)$ \\
\hline
\end{tabular}

table $\mathrm{V}$ shows their final outcome. Six patients in the saline group had inappropriate operations for presumed appendicitis (five) and perforated peptic ulcer (one). Two patients in the papaveretum group were incorrectly diagnosed as having non-specific abdominal pain when first assessed by the registrar. The diagnosis was subsequently changed; and both patients had an inflamed appendix removed within 24 hours of admission. Neither of these appendices was perforated.

There was no difference in the accuracy of localisation of physical signs before and after the injection. The registrar correctly identified 44 patients as having received papaveretum and 41 as having received placebo. These assessments were easily made on the basis of patient comfort, with no conscious attempt at evaluating pupil size. Forty five control subjects required papaveretum for pain relief after the registrar's initial diagnosis and management decision. The duration of stay in hospital was similar after papaveretum (median 5 days (interquartile range 3-9 days)) and after saline ( 6 days (3-10 days)). There were no deaths or side effects from the injection of either group.

TABLE V-Outcome of incorrect diagnoses made by registrar one hour after injection of papaveretum or saline

\begin{tabular}{|c|c|c|}
\hline Diagnosis of registrar & $\begin{array}{c}\text { Management } \\
\text { decision }\end{array}$ & Discharge diagnosis \\
\hline \multirow[b]{2}{*}{$\begin{array}{l}\text { Non-specific abdominal } \\
\text { pain (2) }\end{array}$} & Papaveretum & \\
\hline & Observe (2) & Appendicitis (2) \\
\hline Appendicitis (5) & $\begin{array}{c}\text { Saline } \\
\text { Operate (5) }\end{array}$ & $\begin{array}{l}\text { Non-specific abdominal } \\
\text { pain }(5)\end{array}$ \\
\hline $\begin{array}{l}\text { Perforated peptic ulcer (1) } \\
\text { Biliary }\end{array}$ & $\begin{array}{l}\text { Operate } \\
\text { Observe }\end{array}$ & $\begin{array}{l}\text { Non-specific abdominal pain } \\
\text { Non-specific abdominal pain }\end{array}$ \\
\hline Obstruction & Operate & Perforated peptic ulcer \\
\hline Non-specific abdominal pain & Observe & Biliary colic \\
\hline
\end{tabular}

\section{Discussion}

Our results suggest that the early administration of opiate analgesia is both safe and effective in patients presenting with significant abdominal pain. There was a highly significant reduction in pain experienced after the injection of papaveretum and none after salinethat is, no placebo effect. Most patients (48) reviewed one hour after injection were deemed to be comfortable after papaveretum compared with only nine after saline. These observations show that we had given effective analgesia. Although every attempt was made to maintain the double blind nature of this trial, clear differences in the patient's comfort resulted in an accurate assessment by the registrar of the treatment group each patient belonged to.

Though abdominal tenderness was reduced after papaveretum, there was no change in the localisation of tender areas. This does not support the popular view, held by proponents of early pain relief, that physical signs are unaffected by analgesia and that effective pain relief might in fact facilitate the localisation of tenderness. However, despite the reduction in severity of physical signs after papaveretum, the initial diagnosis and management of patients was not compromised. In fact, analgesia seemed to facilitate accurate diagnosis as there were six unnecessary operations in the control group and none in the treated group. Two patients with acute appendicitis in the analgesia group were initially misdiagnosed as having non-specific abdominal pain. We dismiss this as a significant problem that implies masking of symptoms by opiates. In normal surgical practice the diagnosis of appendicitis may not become clear in a minority of patients until some hours after admission, as occurred in these 
two cases. In the remaining patients who received analgesia no delay in definitive management occurred. Of equal importance was the observation that the surgical registrar's confidence in diagnosing and in deciding on management was not affected by previous administration of papaveretum.

The correct management of patients presenting with acute abdominal pain includes diagnosis, resuscitation, and early operative intervention when indicated. Regrettably, definitive management decisions by surgical registrars are sometimes delayed in less severely ill patients by other clinical commitments such as outpatient clinics and operating lists. Furthermore, many hospitals do not have operating time allocated separately for surgical emergencies during working hours so surgery on patients with acute illness may be delayed until the last elective operating list is finished. These delays, added to the time between seeing a general practitioner and being transferred to hospital, all add to the patient's distress. We believe that this study shows that early pain relief with papaveretum in patients with severe acute abdominal pain does not have any adverse effect on their diagnosis and management. As it is every doctor's duty to relieve suffering when he or she can, patients presenting with acute abdominal pain should not be excluded. The recent recommendations by the Committee on the Safety of
Medicines suggest that morphine is more appropriate for women of childbearing age. ${ }^{13}$

Although not the focus of this study, our results suggest that general practitioners should be encouraged to give pain relief to patients with significant abdominal pain when appropriate. This should not affect subsequent management and will reduce their patients' suffering during transfer to hospital.

The editorial in the $B M F 13$ years ago recommended early pain relief in the management of acute abdominal pain. ${ }^{2}$ This study provides the scientific data to justify this recommendation.

1 Cope Z. Early diagnosis of the acute abdomen. 15th ed, revised by Silen W. New York: Oxford University Press, 1979.

2 Editorial: Analgesia and the acute abdomen. BMF 1979;ii:1093.

Lavelle $M$. Analgesia and the acute abdomen. BMF 1979;ii:1289.

4 Shepherd J. Analgesia and the acute abdomen. BMF 1979;ii: 1289.

5 Dudley H. Analgesia and the acute abdomen. BMF 1979;ii: 1289-90.

6 Quayle J. Analgesia and the acute abdomen. BMF 1979;ii:1290.

7 Hamilton WAP. Analgesia and the acute abdomen. BMF 1979;ii: 1363

8 Fraser ID. Analgesia and the acute abdomen. BMF 1979;ii: 1363.

9 Piper JV. Analgesia and the acute abdomen. $B M$ J 1979;ii: 1443.

10 Cuschieri A. The acute abdomen and disorders of the peritoneal cavity. In: Cuschieri A, Giles GR, Moossa AR, eds. Essential surgical practice. 2nd ed. London: Wright PSG, 1986:1238.

11 Boey JH. The acute abdomen. In: Way LW, ed. Current surgical diagnosis and treatment. Connecticut: Prentice Hall, 1991:440.

12 Zoltie N, Cust MP. Analgesia in the acute abdomen. Ann Roy Coll Surg 1986;68:209-10

13 Committee on Safety of Medicines. Genotoxicity of papaveretum and noscapine. Current Problems 1991; No 31.

(Accepted 7 fuly 1992)
Department of Clinical Chemistry, Glostrup Hospital, University of Copenhagen, DK-2600 Glostrup, Denmark

Kirsten Overgaard, research fellow

Marc Allan Hansen, resident physician Signe Birk Jensen, statistician

Claus Christiansen, head of department

Correspondence and reprint requests to: Dr Overgaard.

BMF 1992;305:556-61

\title{
Effect of salcatonin given intranasally on bone mass and fracture rates in established osteoporosis: a dose-response study
}

\author{
Kirsten Overgaard, Marc Allan Hansen, Signe Birk Jensen, Claus Christiansen
}

\begin{abstract}
Objective-To study the dose related response of salmon calcitonin (salcatonin) given intranasally on bone mass and bone turnover and the effect of salcatonin on rates of fracture in elderly women with moderate osteoporosis.
\end{abstract}

Design-Double blind, placebo controlled, randomised group comparison.

Setting-Outpatient clinic for research into osteoporosis.

Subjects -208 healthy women aged 68-72 years who had a bone mineral content of the distal forearm on average $30 \%$ below the mean value for healthy premenopausal women.

Interventions-The 208 women were allocated randomly in blocks of four to two years of treatment with either salcatonin $50 \mathrm{IU}, 100 \mathrm{IU}$, or $200 \mathrm{IU}$ given intranasally or placebo. All groups received a calcium supplement of $500 \mathrm{mg}$. 32 of the women left the study before its end and 164 women complied with the study criteria throughout.

Main outcome measures-Bone mineral content of the distal forearm and lumbar spine and rates of vertebral and peripheral fractures after two years of treatment.

Results-The average changes in bone mineral content of the spine showed positive outcomes of $1 \%$ ( $95 \%$ confidence interval $-0.1 \%$ to $1 \cdot 5 \%$ ) in the group treated with calcium (placebo) and 3\% $(1.8 \%$ to $4.2 \%$ ) in the group treated with salcatonin $200 \mathrm{IU}$. There was a significant dose related response to salcatonin, manifested by an increase of $1.0 \% / 100 \mathrm{IU}$ $(0 \cdot 2 \%$ to $1 \cdot 7 \%, p=0.008)$. The rate of patients with new fractures was reduced significantly in the women treated with salcatonin to about one third of that in the non-salcatonin treated women (relative risk $0.23(0.07$ to 0.77$))$.

Conclusion-The results suggest that, compared with calcium alone, salcatonin given intranasally reduces the rates of fracture by two thirds in elderly women with moderate osteoporosis. Furthermore, it increases spinal bone mass in a dose dependent manner.

\section{Introduction}

Osteoporosis is a major age related disease affecting millions of women throughout the world. It is characterised by a decreased amount of bone and increased susceptibility to fracture. No certain treatment is yet available for osteoporosis once it is established. Fluoride, which stimulates bone formation, has recently been questioned as to its effect on fracture rates. ${ }^{1}$ Treatments that decrease bone resorption do not necessarily increase bone mass significantly and may not therefore prevent further fractures. Recent evidence has, however, suggested that oestrogen treatment in osteoporotic women significantly increases spinal bone mass ${ }^{2}$ and reduces the rate of vertebral fracture. ${ }^{3}$ Furthermore, it has been indicated that bisphosphonates reduce the incidence of vertebral fractures in osteoporotic women. ${ }^{45}$

The effect of calcitonin on the rate of fracture remains unknown, although injectable calcitonin has been approved for the treatment of established osteoporosis. ${ }^{6}$ Calcitonin inhibits osteoclastic activity and in the long term it affects the number of osteoclasts by inhibiting the production of osteoclast precursors. ${ }^{8}$ The intranasal formulation was developed with the aim of reducing the incidence of systemic reactions and the 